\title{
Some Mechanisms of the Noncontact Anterior Cruciate Ligament (ACL) Injury among Male Sport Activities
}

\author{
Kasbparast Mehdi ${ }^{1 *}$ and Shokrgozar Alireza ${ }^{2}$ \\ Faculty of Physical Education and Sport Sciences, Islamic Azad University, Iran \\ *Corresponding author: Kasbparast Mehdi, Faculty of Physical Education and Sport Sciences, Islamic Azad University, Karaj branch, Iran

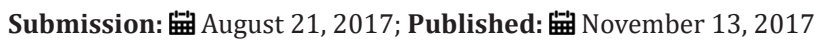

\begin{abstract}
In this study tried to investigate of some Anterior Cruciate Ligament (ACL) injury mechanisms amongmale sport activities. Of course an understanding of the noncontact ACL injuries mechanism has lagged behind diagnosis and treatment. However, a growing research implicates hormonal, anatomic, environmental, and biomechanical factors that may predispose athletes to these injuries. For this study selected 839 athlete for assess ACL injury mechanism by two different method: (A)Questionnaire and (B) Interview that information collected among athlete who were play soccer, volleyball, futsall, basketball, wrestling, ski and gymnastics. Our results indicate $52.6 \%$ of injuries occur during practices and $47.4 \%$ during competition. It also became clear that $72.3 \%$ of injuries are due to noncontact mechanism, $4.7 \%$ by accidents and $23 \%$ with unknown mechanism. Furthermore Dynamic alignment at the time of the injury included: Knee-in \& Toe-out 47.1\%, Knee-out \& Toe-in 17.7\%, and Hyperextension $11.4 \%$.
\end{abstract}

The ACL prevents the femur from moving forwards during weight bearing. It also helps to prevent rotation of the joint. Injury of the ACL most often occurs when an athlete is pivoting, decelerating suddenly or landing from a jump. The injury can also be caused by another player falling across the knee. ACL injuries are, probably, the most common devastating knee ligament injuries amongst sports persons. Usually these injuries are isolated, mainly in noncontact sports, but may often be a part of more complex ligamentous injuries. They occur more often in contact sports, such as football, and road traffic accidents. These injuries are most likely to lead to the need for surgery. So that's why it seems necessary to understand the ACL mechanism injury.

Keywords: Anterior cruciate ligament; Sport activities; Injury

\section{Introduction}

Anterior cruciate ligament (ACL) injury in professional athletes can cause long lay-off from sports Busfield et al. [1], Shah et al. [2], Walden et al. [3] and may be career threatening Erickson et al. [4] On average, one player will suffer an ACL injury every second season in a professional men's football team squad Walden et al. [3] Serious injuries have not dropped in men's professional football in the past decade Ekstrand et al. [5] and prevention of ACL injury is a priority area within sports medicine/sports physiotherapy research Engebretsen et al. [6]. Anterior cruciate ligament (ACL) is a common injury among young sportsmen and sportswomen, with a reported annual incidence in the general population of 0.8 per 1000(Potter et al., 2012), but as high as 100 per 1000 in professional footballers Lohmander et al. [7]. The anterior cruciate ligament (ACL) is frequently ruptured in European team handball, US college and high school sports (basketball, soccer, and gymnastics), and other sports and levels Arendt et al. [8], Arendt, Hutchinson et al. [9], Myklebust et al. [10], Myklebust et al. [11], ACL injuries are most commonly sustained with the noncontact loading of a valgus knee while twisting in the opposite direction producing a forced internal rotation of the tibia Shin et al. [12]

The risk factors for an ACL injury have been reported from the standpoints of the environment, anatomical structure, hormones, and biomechanics Anderson et al. [13], Arendt, Boden et al. [14], Chaudhari et al. [15]. Anterior cruciate ligament (ACL) injuries are common among athletes and occur primarily in individuals involved in sports with knee pivoting movements such as soccer, football, team handball, basketball and alpine skiing. ACL injuries are functionally disabling and their natural history is unclear. They predispose the knee to subsequent injuries and the early onset of osteoarthritis Beynnon et al. [16]. Due to the fact that female athletes are 4-6 times more likely to sustain an ACL injury than their male counterparts when participating in the same sports, most studies evaluating risk factors focus on females Hewett et al. [17], Hewett et al. [18]. Approximately $70 \%$ of all ACL injuries are non-contact injuries Griffin et al. [19]. Risk factors for an ACL non-contact injury can be divided into environmental, anatomic, hormonal and biomechanical. Environmental or extrinsic factors refer to how the friction between shoes and the playing surface has implications for the risk of sustaining an ACL injury Strand et al. [20], Olsen et al. [21].

The dimensions of the intercondylar notch have been extensively studied in relation to ACL injuries. Due to the different methods employed to obtain data on notch width, results are difficult to interpret. It has been demonstrated that the notch 
width measurement of bilateral knees with ACL injury is smaller than that of unilateral knees with ACL injury, and notch widths of bilateral and unilateral knees with injury to the ACL are smaller than those of normal controls. This implies a strong association between notch width and ACL injury Griffin et al. [22]. Hormonal differences between men and women could to some extent explain the discrepancy in injury rates. The risk of an ACL injury seems to be higher in the preovulatory than the postovulatory phase of the menstrual cycle Wojtys et al. [23], Zazulak et al. [24], Beynnon et al. [25]. Results from measurement of estrogen, progesterone and luteinizing hormone metabolites levels at the time of the anterior cruciate ligament tear have indicated that women had a significantly greater than expected percentage of anterior cruciate ligament injuries during midcycle (ovulatory phase) and a less than expected percentage during the luteal phase of the menstrual cycle Wojtys et al. [26]. Also recent research in the area of ACL injury risk factors has centered on neuromuscular performance.

Neuromuscular control of the knee involves a complex interplay between the neurologic system and the muscles that cross the knee joint. Perhaps in noncontact ACL injury, expected motor recruitment patterns that control the knee are altered, which lead to injury. This aberration may result in a faulty or delayed neurologic signal to the knee instead of a protective muscle response. The balance of muscle power and recruitment pattern between the quadriceps

Table 1: Male sports activities participation $(\mathrm{n}=839)$.

\begin{tabular}{|c|c|c|c|c|c|}
\hline Sport & $\mathbf{N}$ & Rate(\%) & Height(M) & Weight(Kg) & Age(Yrs) \\
\hline Soccer & 268 & 32 & 1.73 & 72.3 & 24.7 \\
\hline Volleyball & 183 & 21.8 & 1.96 & 89.6 & 21.5 \\
\hline Futsal & 126 & 15 & 1.71 & 71.8 & 23.9 \\
\hline Basketball & 96 & 11.4 & 1.88 & 86.9 & 21.8 \\
\hline Wrestling & 88 & 10.5 & 1.68 & 70.3 & 25.2 \\
\hline Ski & 54 & 6.4 & 1.74 & 72.5 & 22.4 \\
\hline Gymnastics & 24 & 2.9 & 1.67 & 65.4 & 19.5 \\
\hline
\end{tabular}

All injured players were interviewed during the 2010-2013 to compare player recall with the questionnaire. The interview data were also used to check whether the questionnaire we obtained was a representative sample. The entire athletes were diagnosed as having an ACL injury confirmed by magnetic resonance imaging (MRI) and/or an arthroscopic procedure. Approximately seventy five percent of the subjects visited the clinic within one month, and 25 percent of the subjects visited the clinic within one week after an ACL injury incident. We classified the activity of the subject at the time of the ACL injury in two categories (A) competitions (B) practice. Also we classified the injury mechanism. In three categories (A) Noncontact: No contact with another person or things at the time of the injury (B) Accident: Particular situations during sports activities such as skiing and (C) Unknown: The injury mechanism data missing in medical records, and dynamic alignment at the time of the injury. We classified the dynamic alignment at the time of the injury into six categories Kawano et al. [33] and the hamstring muscles is crucial to functional knee stability. The quadriceps, as ACL antagonists, may contribute to ACL injury. Some researchers have reported that quadriceps contraction increases ACL strain between $10^{\circ}$ and $30^{\circ}$ of knee flexion Torzilli et al. [27], Arms et al. [28], Shoemaker et al. [29], Draganich et al. [30]. ACL injuries often occur when landing from a jump, cutting or decelerating. A combination of anterior tibial translation and lower extremity valgus are probably important components of the injury mechanism in these athletes. It has been demonstrated that most non-contact ACL injuries occurred when the frontal knee valgus angle increased abruptly from 3 to $16^{\circ}$ during 30-40 ms Griffin LY et al. [31]. Approximately $30 \%$ of all ACL injuries result from direct contact with another player or object Potter HG [32]. Although several authors have speculated on the etiology of the 70\% of ACL injuries that do not result from direct contact, the basic mechanism for this injury still eludes us.

\section{Materials and Methods}

Data were collected from 2 different ways, from the questionnaire $(n=634)$ and through interviews with injured players $(n=205)$. Information was collected prospectively through the 2010-2013. The sport activities that were considered for the study included: soccer, volleyball, futsall, basketball, wrestling, ski and gymnastics (Table 1). i. Knee-in \& Toe-out: Knee valgus and foot abduction position

ii. Knee-out \& Toe-in: Knee varus and foot adduction position

iii. Hyperextension: Hyper-extended knee position

iv. Unclear: Injury mechanism that was not expressed clearly by the patients

v. Unknown: The injury mechanism data missing in medical records

vi. Other

\section{Results}

Our result showed an ACL injury occurred more often during a practice than during competition. Activity at the time of the injury (Table 2), the number of subjects who had the injury during "Practice "was the largest (441), accounting for 52.6\% of all 
the subjects. The number of subjects who had the injury during "Competition" accounted for $47.4 \%$ (398). No significant difference was found between sports activities.

Table 2: Activity at the time of the injury.

\begin{tabular}{|c|c|c|}
\hline Time of Injury & Total(839) & Rate (\%) \\
\hline Practice & 441 & 52.6 \\
\hline Competition & 398 & 47.4 \\
\hline
\end{tabular}

We obtained the information of the injury mechanism from 839 subjects (Table 3). The number of "Noncontact" cases was 607, Accident" cases were 39 and unknown cases were 193.our results indicate that the number of noncontact injury among soccer and futsal was largest (248).

Table 3: Injury mechanism at the time of the injury.

\begin{tabular}{|c|c|c|}
\hline Injury Mechanism & Total(839) & Rate (\%) \\
\hline Noncontact & 607 & 72.3 \\
\hline Accident & 39 & 4.7 \\
\hline Unknown & 193 & 23 \\
\hline
\end{tabular}

We investigated the dynamic alignment at the time of the injury in 839 subjects (Table 4). Among all the subjects, the number of the subjects with the alignment of Knee-in \& Toe-out was the largest (395), Knee-out \& Toe-in was (148) and Hyperextension was (96), Unclear was (107), Unknown was (52) and Others was (41). We found no significant difference in the dynamic alignment at the time of the injury between sport activities.

Table 4: Dynamic alignment at the time of the injury.

\begin{tabular}{|c|c|c|}
\hline Position & Total(839) & Rate (\%) \\
\hline Knee-in \& Toe-out & 395 & 47.1 \\
\hline Knee-out \& Toe-in & 148 & 17.7 \\
\hline Hyperextension & 96 & 11.4 \\
\hline Unclear & 107 & 12.7 \\
\hline Unknown & 52 & 6.2 \\
\hline Others & 41 & 4.9 \\
\hline
\end{tabular}

The results of this study showed that regardless of the Activity at the time of the injury (practice, Competition), Injury mechanism at the time of the injury and Dynamic alignment at the time of the injury, the most ACL injuries occur in ski. Although the skiers in study were gust 54 , but 41 of them had an ACL injury (76\%). ACL injury among volleyball was lowest with only 69 of 183 people have an ACL injury (37.8\%). In Figure 1 are shown sport activities and percent of ACL injury.

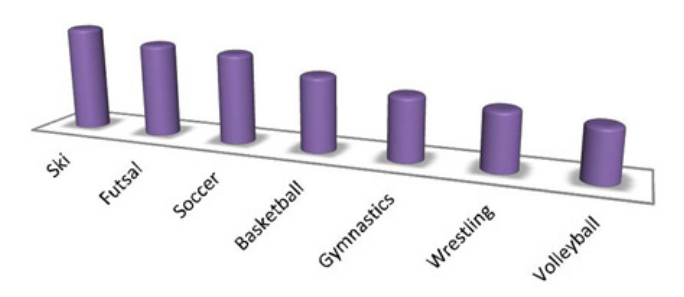

Figure1: Rate of ACL injury among some male sport activities.

\section{Discussion}

The function of the ACL is to stabilize the knee joint, prevent abnormal movements, and steer the movement of the knee Nordin et al. [34]. The ACL prevents forward translation of the tibia relative to the femur, and cadaver studies have shown that at $30^{\circ}$ of knee flexion the ACL represents $85 \%$ of the total capsular and ligamentous resistance Butler. An ACL tear is most often a sportsrelated injury. ACL tears can also occur during rough play, mover vehicle collisions, falls, and work-related injuries. About $80 \%$ of sports-related ACL tears are "non-contact" injuries. This means that the injury occurs without the contact of another athlete, such as a tackle in soccer. Most often ACL tears occur when pivoting or landing from a jump. The knee gives-out from under the athlete when the ACL is torn.

Our result showed an ACL injury occurred more often during a practice than during competition. The situations during a competition and a practice are different in many respects. Athletes usually spend a much longer time in practice than in competition. Along with longer commitment, athletes usually challenge new team formation and technique during a practice rather than during a competition, which might increase the risk of injury. However, a more stressful situation might be imposed on the athletes during a competition than during a practice both physically and mentally. The current result might reflect the increased physical and mental stress during competitions but with regard the time of practice longer than competition, there is a greater risk of injury during practice.

The current result also showed that noncontact cases were the most common in soccer. The investigation on the dynamic alignment at the time of the injury revealed that the knee-in \& toe-out alignments were most often reported. In retrospective interviewing studies, the subjects often encounter difficulty in recalling the dynamic alignment at the time of the injury, which may be related to the passage of time between the injury and the interview. The interview was usually held long after the injury occurred; for example, Boden et al. [35] reported that the interview was held 3.4 years after the injury on average. In addition, whether the information obtained is accurate or not may depend on how the subject described the dynamic alignment at the time of the injury. Therefore, there might be questions about the accuracy of the information obtained in the retrospective interviewing study Krosshaug et al. [36], Shimokochi et al. [37]

This study with the results obtained from interview also showed that gaining a better understanding of ACL injury mechanism provides greater insight into possible predisposing factors McNair et al. [38], Feagin et al. [39]. Noncontact ACL injuries typically occur during deceleration and change of direction with the foot fixed Knee torsion that results from making a sudden directional change on a planted foot has been implicated as a cause of ACL tears. We confirmed that the data from both sources (questionnaire and interview) exactly matched each other. If the data was unmatched, we regarded the description of the ACL injury mechanism as an "unclear" dynamic alignment. The subjects at the interview were 
able to recall the mechanism of their ACL injury. A noncontact mechanism was described in $24.5 \%$ of the athletes via interview. Data such as contact versus noncontact, position of the knee and lower leg, direction of knee collapse, direction of body twisting, and other events were recorded.

The number of variables an athlete must respond to in team sports may explain the higher incidence of injuries in sports such as soccer, futsall, volleyball and basketball. Though the exact moment of injury was impossible to determine from interview, the position of the leg before collapse in most of noncontact injuries was near foot strike with the knee in slight flexion. None were associated with a sharp, pivoting motion of the body around a planted leg or varus collapse of the knee. Valgus collapse of the knee in varying degrees was noted in most injuries. These findings have several important implications.

Sharp changes in direction, landing, and rapid deceleration are normally repeated thousands of times in athletic endeavors without injury. The difference for athletes who sustain ACL injuries may be that abnormal motor patterns cause the quadriceps to preferentially activate before the hamstrings. Simonsen et al [40] found that even with maximal contraction of hamstrings, the muscles were not able to reduce the forces on the ACL during cutting movements in young, well-trained team handball players. Some researchers discussed the mechanical stress imposed on the knee joint on the basis of the MR images after an ACL injury Fayad et al. [41], Viskontas et al. [42]. Due to these previous findings and our current finding we speculated that the "valgus knee" observed in an action with "Knee-in \& Toe-out" is related to the occurrence of a noncontact injury and that both internal and external rotations of the tibia may occur at the time of an ACL injury.

Although knee external rotation is often described in the mechanisms for ACL injuries, the literature indicates that knee internal rotation may be an equally, if not more important, motion to protect the ACL. Further, the application of knee valgus loading during a sudden decelerating, weight-bearing task, such as landing, may also increase ACL loading Withrow et al. [43]. Because a combination of knee external rotation and valgus motions may impinge the ACL against the femoral intercondylar notch Fung et al. [44] and because these motions have been often observed during noncontact ACL injury, knee external rotation remains an important consideration for ACL injury Ferretti et al. [45], Olsen et al. [46].

Also, the mechanism of ACL injury in skiing is different from that in jumping, running, and cutting sports such as football, soccer, basketball and volleyball. In skiing, most ACL injuries result from internal rotation of the tibia with the knee flexed greater than $90^{\circ}$, a position that results when a skier, falling backward, catches the inside edge of the tail of the ski Ettlinger et al. [47]. There is a pressing need to improve public and participant awareness of the risk of ACL injury and the possibilities for prevention. The morbidity from ACL injuries in the athletic population is of great concern. Furthermore, the economic impact of these injuries adds significantly to our rising medical costs.
Therefore, efforts to prevent or at least decrease the rate of occurrence of these injuries seem prudent. Until recently, attempts to develop prevention programs centered on first clearly defining risk factors and injury mechanisms. Although these research efforts have yielded much information, they have not, with the exception of research efforts in some sport activities, resulted in a clear understanding of the cause of non-contact ACL injuries. So it seems, according to the findings of this study should be planned prevention programs to reduce ACL injury. Prevention programs designed to increase neuromuscular control, improve balance, and teach avoidance strategies for at risk situations appear to be effective in decreasing injury rates.

\section{References}

1. Busfield BT, Kharrazi FD, Starkey C, Lombardo SJ, Seegmiller J, et al. (2009) Performance outcomes of anterior cruciate ligament reconstruction in the National Basketball Association. Arthroscopy 25(8): 825-830.

2. Shah VM, Andrews JR, Fleisig GS, McMichael CS, Lemak LJ, et al. (2010) Return to play after anterior cruciate ligament reconstruction in National Football League athletes. Am J Sports Med 38(11): 2233-2239.

3. Waldén M, Hägglund M, Magnusson H, Ekstrand J, (2011) Anterior cruciate ligament injury in elite football: a prospective three-cohort study. Knee Surg Sports Traumatol Arthrosc 19(1): 11-19.

4. Erickson BJ, Harris JD, Cvetanovich GL, Bach BR, Bush Joseph CA, et al. (2013) Performance and return to sport after anterior cruciate ligament reconstruction in male Major League Soccer players. Orthop J Sports Med 1(2): 2325967113497189.

5. Ekstrand J, Hägglund $M$, Kristenson $K$, Magnusson $H$, Waldén $M$, et al. (2013) Fewer ligament injuries but no preventive effect on muscle injuries and severe injuries: an 11-year follow-up of the UEFA Champions League injury study. Br J Sports Med 47: 732-737.

6. Engebretsen L, Bahr R, Cook JL, Derman W, Emery CA, et al. (2014) The IOC Centres of Excellence bring prevention to sports medicine. Br J Sports Med 48: 1270-1275.

7. Lohmander LS, Englund PM, Dahl LL, Roos EM (2007) The long-term consequence of anterior cruciate ligament and meniscus injuries: osteoarthritis. Am J Sports Med 35(10): 1756-1769.

8. Arendt E, Agel J, Dick R (1999) Anterior cruciate ligament injury patterns among collegiate men and women. J Athl Train 34(2): 86-92.

9. Hutchinson MR, Ireland ML (1995) Knee injuries in female athletes. Sports Med 19(4): 288-302.

10. Myklebust G, Maehlum S, Engebretsen L, Strand T, Solheim E, et al. (1997) Registration of cruciate ligament injuries in Norwegian top level team handball: a prospective study covering two seasons. Scandinavian. Journal of Medicine \& Science in Sports 7(5): 289-292.

11. Myklebust G, Maehlum S, Holm I, Bahr R (1998) A prospective cohort study of anterior cruciate ligament injuries in elite Norwegian team handball. Scand J Med Sci Sports 8(3): 149-153.

12.Shin CS, Chaudhari AM, Andriacchi TP (2011) Valgus plus internal rotation moments increase anterior cruciate ligament strain more than either alone. Med Sci Sports Exerc 43(8): 1484-1491.

13. Anderson AF, Lipscomb AB, Liudahl KJ, Addlestone RB (1987) Analysis of the intercondylar notch by computed tomography. Am J Sports Med 15(6): 547-552.

14.Krosshaug T, Nakamae A, Boden BP, Engebretsen L, Smith G, et al. (2007) Mechanisms of anterior cruciate ligament injury in basketball: video analysis of 39 cases. Am J Sports Med 35(3): 359-367. 
15. Chaudhari AM, Lindenfeld TN, Andriacchi TP, Hewett TE, Riccobene J, et al. (2007) Knee and hip loading patterns at different phases in the menstrual cycle: implications for the gender difference in anterior cruciate ligament injury rates. Am J Sports Med 35(5): 793-800.

16. Beynnon BD, Johnson RJ, Abate JA, Fleming BC, Nichols CE, et al. (2005) Treatment of anterior cruciate ligament injuries, part I. Am J Sports Med 33(10): 1579-1602.

17. Hewett TE, Zazulak BT, Myer GD, Ford KR (2005) A review of electromyography activation levels, timing differences, and increased anterior cruciate ligament injury incidence in female athletes. $\mathrm{Br}$ Sports Med 39(6): 347-350.

18. Hewett TE, Ford KR, Myer GD (2006) Anterior cruciate ligament injuries in female athletes: Part 2, a meta-analysis of neuromuscular interventions aimed at injury prevention. Am J Sports Med 34(3): 490498.

19.Griffin LY, Agel J, Albohm MJ, Arendt EA, Dick RW, et al. (2000) Noncontact anterior cruciate ligament injuries: risk factors and prevention strategies. J Am Acad Orthop Surg 8(3): 141-150.

20.Strand T, Tvedte R, Engebretsen L, Tegnander A (1990) Anterior cruciate ligament injuries in handball playing. Mechanisms and incidence of injuries. Tidsskr Nor Laegeforen 110(17): 2222-2225.

21. Olsen OE, Myklebust G, Engebretsen L, Holme I, Bahr R, et al. (2003) Relationship between floor type and risk of ACL injury in team handball. Scand J Med Sci Sports 13(5): 299-304.

22.Griffin LY, Albohm MJ, Arendt EA, Bahr R, Beynnon BD, et al. (2006) Understanding and preventing noncontact anterior cruciate ligament injuries: a review of the Hunt Valley II meeting, January 2005. Am J Sports Med 34(9): 1512-1532.

23.Wojtys EM, Huston LJ, Lindenfeld TN, Hewett TE, Greenfield ML (1998). Association between the menstrual cycle and anterior cruciate ligament injuries in female athletes. Am J Sports Med 26(5): 614-619.

24.Zazulak BT, Paterno M, Myer GD, Romani WA, Hewett TE (2006) The effects of the menstrual cycle on anterior knee laxity: a systematic review. Sports Med 36(10): 847-862.

25.Beynnon BD, Johnson RJ, Braun S, Sargent M, Bernstein IM, et al. (2006) The relationship between menstrual cycle phase and anterior cruciate ligament injury: a case-control study of recreational alpine skiers. Am J Sports Med 34(5): 757-764.

26. Wojtys EM, Ashton Miller JA, Huston L (2002) A gender-related difference in the contribution of the knee musculature to sagittal-plane shear stiffness in subjects with similar knee laxity. J Bone Joint Surg Am 84(1): $10-16$

27. Torzilli PA, Deng X, Warren RF (1994). The effect of joint- compressive load and quadriceps muscle force on knee motion in the intact and anterior cruciate ligament-sectioned knee. Am J Sports Med 22(1): $105-112$.

28. Arms SW, Pope MH, Johnson RJ, Fischer RA, Arvidsson I, et al. (1984) The biomechanics of anterior cruciate ligaments rehabilitation and reconstruction. Am J Sports Med 12(1): 8-18.

29.Shoemaker SC, Adams D, Daniel DM, Woo SL (1993) Quadriceps / anterior cruciate graft interaction: an in vitro study of joint kinematics and anterior cruciate ligament graft tension. Clin Orthop Relat Res (294): 379-390.

30. Draganich LF, Vahey JW (1990) An in vitro study of anterior cruciate ligament strain induced by quadriceps and hamstrings forces. J Orthop Res 8(1): 57-63.
31.Griffin LY1, Albohm MJ, Arendt EA, Bahr R, Beynnon BD, et al. (2006) Understanding and preventing noncontact anterior cruciate ligament injuries: a review of the Hunt Valley II meeting, January 2005. Am J Sports Med 34(9): 1512-1532.

32.Potter HG, Jain SK, Ma Y, Black BR, Fung S, et al. (2012) Cartilage injury after acute, isolated anterior cruciate ligament tear: immediate and longitudinal effect with clinical/MRI follow-up. Am J Sports Med 40(2): 276-285.

33. Kawano T, Nomura A, Gamada K, Kurosawa H (1998) Conservative treatment from the view points of sports motion and Functional Orthopaedic Insole. Orthopaedic Surgery and Traumatology 41(10): 1195-1204.

34.Nordin M, Frankel VH (2001) Basic Biomechanics of the Musculoskeletal System.3rd ed. Philadelphia, Lippincott Williams \& Wilkins, Philadelphia, USA.

35. Boden BP, Dean GS, Feagin JA Jr, Garrett WE Jr (2000) Mechanisms of anterior cruciate ligament injury. Orthopedics 23(6): 573-578.

36. Krosshaug T, Andersen TE, Olsen OE, Myklebut G, Bahr R, et al. (2005) Research approaches to describe the mechanisms of injuries in sport: limitation and possibilities. Br J Sports Med 39(6): 330-339.

37. Shimokochi Y, Shultz SJ (2008) Mechanisms of noncontact anterior cruciate ligament injury. J Athl Train 43(4): 396-408.

38. McNair PJ, Marshall RN, Matheson JA (1990) Important features associated with acute anterior cruciate ligament injury. N Z Med J 103(901): 537-539.

39. Feagin JA, Lambert KL (1985) Mechanism of injury and pathology of anterior cruciate ligament injuries. Orthop Clin North Am 16(1): 41-45.

40.Simonsen EB, Magnusson SP, Bencke J, Woo SL (2000) Can the hamstring muscles protect the anterior cruciate ligament during a side-cutting maneuver? Scand J Med Sci Sports 10(2): 78-84.

41. Fayad LM, Parellada JA, Parker L, Schweitzer ME (2003) MR imaging of anterior cruciate ligament tears: is there a gender gap? Skeletal Radiol 32(11): 639-646.

42.Viskontas DG, Giuffre BM, Duggal N, Graham D, Parker D, et al. (2008) Bone bruises associated with ACL rupture: correlation with injury mechanism. Am J Sports Med 36(5): 927-933.

43. Withrow TJ, Huston LJ, Wojtys EM, Ashton Miller JA (2006). The effect of an impulsive knee valgus moment on in vitro relative ACL strain during a simulated jump landing. Clin Biomech (Bristol, Avon) 21(9): 977-983.

44.Fung DT, Zhang LQ (2003) Modeling of ACL impingement against the intercondylar notch. Clin Biomech (Bristol, Avon) 18(10): 933-941.

45. Ferretti A, Papandrea P, Conteduca F, Mariani PP (1992) Knee ligament injuries in volleyball players. Am J Sports Med 20(2): 203-207.

46. Olsen OE, Myklebust G, Engebretsen L, Bahr R (2004) Injury mechanisms for anterior cruciate ligament injuries in team handball: a systematic video analysis. Am J Sports Med 32(4): 1002-1012.

47.Ettlinger CF, Johnson RJ, Shealy JE (1995) A method to help reduce the risk of serious knee sprains incurred in alpine skiing. Am J Sports Med 23(5): 531-537. 